\title{
By Means of Unmanned Aerial Vehicle (UAV) -Based Photogrammetry, Observing, Analyzing and Reporting of the Big Construction Projects, Ethiopia Application
}

\author{
Sinan Altinisik, Semih Seckin Kavlak \\ Birlik Harita Imar Insaat ve Ticaret Ltd. Sti., Ankara, Turkey \\ Email address: \\ sinan.altinisik@birlikharita.com.tr (S. Altinisik), semih.kavlak@birlikharita.com.tr (S. S. Kavlak) \\ To cite this article: \\ Sinan Altinisik, Semih Seckin Kavlak. By Means of Unmanned Aerial Vehicle (UAV) -Based Photogrammetry, Observing, Analyzing and \\ Reporting of the Big Construction Projects, Ethiopia Application. American Journal of Remote Sensing. Vol. 5, No. 2, 2017 , pp. 16-23. \\ doi: $10.11648 /$ j.ajrs.20170502.12
}

Received: September 4, 2017; Accepted: September 28, 2017; Published: November 6, 2017

\begin{abstract}
The method of map production by using UAV photogrammetry is widely-used in Turkey and World in recent years. With the developing technology, the capabilities of UAV platforms increase in parallel with the scale of projects, which are done by using UAVs, almost reaches to enough magnitude in order to compete with manned aircraft platforms. In the article, it has been discussed in observing, analyzing and reporting of cut and fill productions within the scope of $270 \mathrm{~km}$ railway Project in Ethiopia. In the result of article, it has been evaluated that the maps required by large-scale construction projects can be produced by using UAVs within high accuracies and it has some advantages in time and cost.
\end{abstract}

Keywords: UAV, Photogrammetry, Railway, Construction, Mapping, DTM, DSM, Observing, Analyzing

\section{Introduction}

\subsection{UAV Based Photogrammetry}

UAV based systems; owing to cost-effective positional data, in the field of geoscience, every day it draws more attention. With the developing platforms and the software used, the usage areas of UAV in the mapping sector are rapidly increasing day by day.

There are many current applications for UAV in photogrammetry and remote sensing, and that the current trend in increasing demand for UAV geospatial systems appears unstoppable [1].

\subsection{History}

UAV-based remote sensing studies have been carried out for many decades. In the late 1970's fixed wing remote controlled aircrafts have been investigated for first motorized UAV photogrammetry experiments [2].

In our country, it has started to be used for the last five years. Despite the fact that it is used very shortly in our country, the size and number of the projects realized with UAV based photogrammetry are rapidly increasing thanks to the capabilities of the UAV platforms.
Recently, unmanned aerial vehicles (UAVs) have evolved to off-the-shelf platforms for remote sensing applications and photogrammetric data acquisition. Early work started back in the 2000 with mainly model air-planes and helicopters [3].

The reason why the UAV system is so important is that UAV systems that integrate with GNSS technology support RTK (Real Time Kinematic) and PPK (Post Process Kinematic) measurement methods.

\subsection{Usage Areas}

Thanks to the speed, cost and accuracy advantages provided by the UAV-based photogrammetry, UAV systems are used in every area in which mapping are needed commonly.

a. Current Map Production

b. Orthophoto Production

c. Construction Mapping / Production Monitoring reporting

d. Monitoring of Disaster Areas

e. Military Purpose Map and Orthophoto productions

f. 3D terrain Model and Orthophoto Production.

It can be considered as the main application areas. 


\subsection{Software Used}

The most important component of the software required for mapping with the UAV-based photogrammetry is the photogrammetric bundle block adjustment software that calculates the geodetic coordinates $(\mathrm{X}, \mathrm{Y}, \mathrm{Z})$ and orientation Yaw, Pitch, Roll angles (Omega, Phi, Kappa) of the photo center points.

Another factor that affects accuracy is the accurate and precise calculation of camera parameters. This is primarily related to the calibration/quality of the camera and lens used, and the adjustment software also has a direct impact. By means of the camera parameters obtained as a result of the adjustment of the captured aerial photographs, the distortions in the images are eliminated and the desired accuracies are obtained.

The related softwares use mostly the "Bundle Block Adjustment" method. The most common softwares being used are listed below.

Table 1. UAV Software.

\begin{tabular}{lll}
\hline Software & Country & Price (\$) \\
\hline Pix4D & Sweden & $8.700 \$$ \\
Agisoft Photoscan & Russia & $3.499 \$$ \\
Menci Photogrametry & Italy & $4.750 €$ \\
3DF Zafyr Aerial & Italy & $4.200 \$$ \\
\hline
\end{tabular}

The softwares used generally produces similar results. Based on the comparison results obtained in our previous tests, Pix4D software is preferred in our projects.

\section{Ethiopia Railway Project}

\subsection{Project Area}

The project area (Figure 1) consists of a total of $270 \mathrm{~km}$ of railway construction routes between the Awash and Weldia regions in Ethiopia.

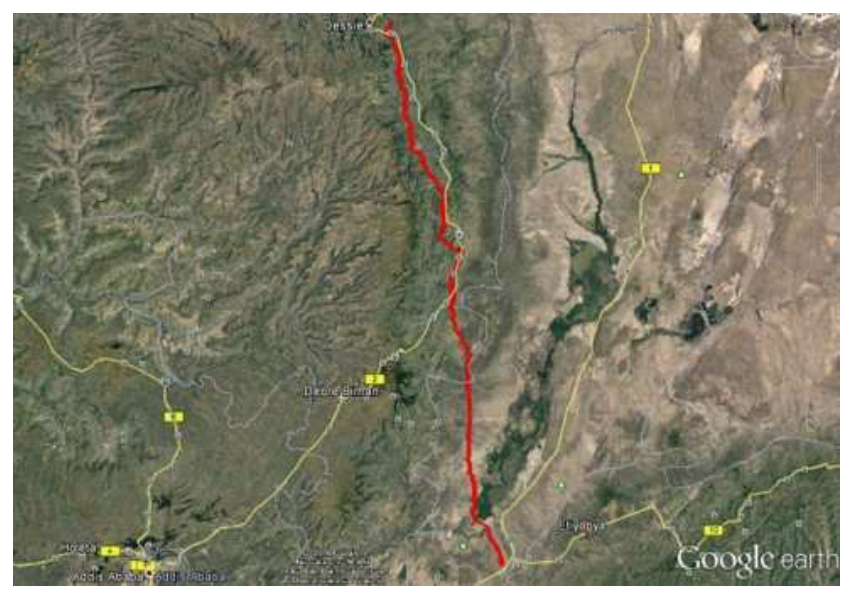

Figure 1. Project Route.

\subsection{Why the Project Needed}

Due to the fact that the ongoing excavation works in the project area are fragmented and the duration of project construction is short, some weaknesses such as monitoring of production made and budgeting are experienced.

Due to the short duration of the construction works compared to the project size and many worker working on the site at the same time, the construction works continue along the route very quickly. Within the scope of fast ongoing construction works, the following requirements were needed.

a. Early detection of erroneous construction,

b. Controlling payments made for subcontractors,

c. Linking the building process with the project calendar in a more healthy way

d. Contributing to team / equipment planning by calculating remaining construction quantities

e. More effective management of the project budget

It has been decided to make precise maps with UAV, in the direction of all these needs. The main reasons for choosing $\mathrm{UAV}$ can be listed as follows:

a. Mobilization of the UAV system is easy, fast and less costly.

b. Flight permits of the UAV system are much easier and faster.

c. They are affected much less than meteorological conditions.

With this project, it is aimed to monitor and report of production on the construction site by making flights at intervals of two months. This will ensure that the top management is able to make a health decision on issues such as updating the project budget, progress payments and revision of the project plan.

\section{Project Phases}

In carrying out the project, the following work steps were followed.

\subsection{Determination of Project Requirements}

Project parameters were determined by taking the following criteria into consideration.
a. Project purpose
b. Project size
c. Topography and meteorological conditions,
d. Relevant civil aviation regulation
e. Target accuracy / precision values
f. Project duration
g. Project budget
h. Expected products
The specified project parameters are as follows;

Table 2. Project Parameters

\begin{tabular}{ll}
\hline Parameter & Value \\
\hline Project Length & $270 \mathrm{~km}$ \\
Corridor Width & $80 \mathrm{~m}-340 \mathrm{~m}$ \\
Photo GSD & $5 \mathrm{~cm}$ \\
Flight Height & $205 \mathrm{~m}$ \\
Target Accuracy & $<10 \mathrm{~cm}$ (horizontal and vertical) \\
\hline
\end{tabular}




\subsection{Geodetic Studies}

In the project area, in addition to the currently used ground control points (GCP) for the construction works, new control points (Figure 2) have been established.
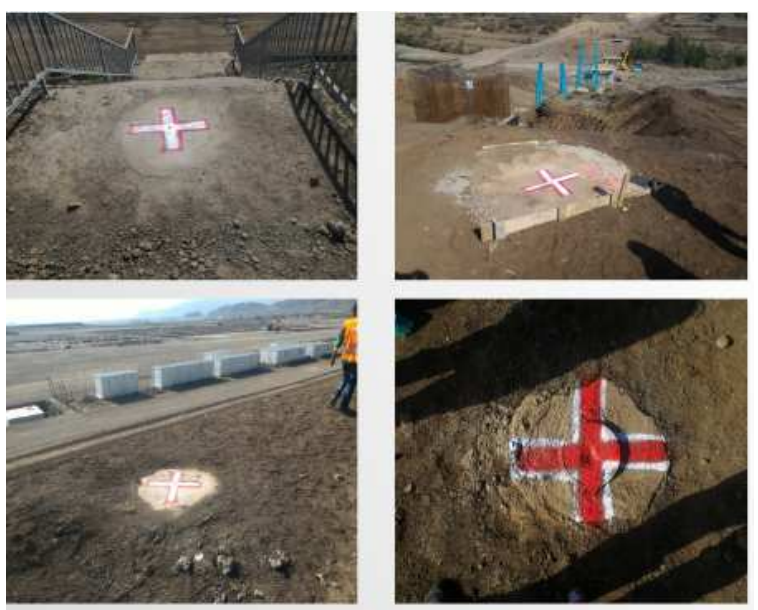

Figure 2. A Few Examples of Ground Control Points Air Marking.

Approximately in every $2000 \mathrm{~m}$, ground control points are established and the geodetic coordinates of these points are determined by the RTK (Real Time Kinematic) measurement method.

All ground control points are painted with white color as air marking and made ready for flight. 588 GCP were established in the all of project area.

\subsection{Preparation of Flight Plans and Flight}

\subsubsection{Criteria's of Flights Plan}

The flight planning is the first step in photogrammetric project. In order to use new technologies and to get optimum profits, it is required to prepare an efficient flight plan. Since GPS technology has been used successfully in photogrammetry, planning of a flight for acquiring aerial photographs cannot be considered as separately [4]. Nowadays, most of the planes, designed for aerial photography, have GPS and computer aided flight management system. To use these systems effectively, the first and the basic principle is preparing the flight plans in digital formats and entering these data to the system digitally.

A flight plan (Figure 3) consists of the following criteria's.

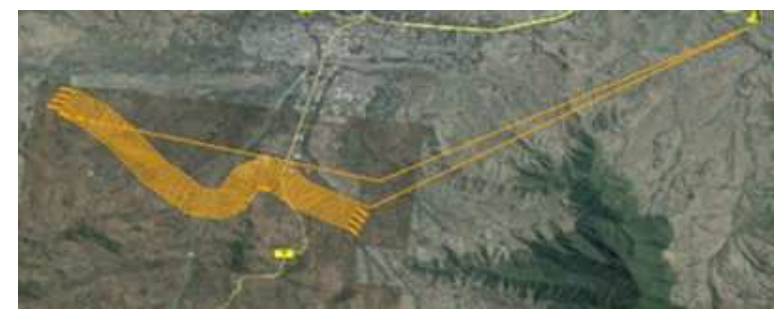

Figure 3. An Example of Flight Plan.

a. Desired Ground Sampling Distance (GSD)

b. Project boundaries c. Topography

d. Camera and lens used (sensor size and focal length)

e. Flight endurance of the UAV

f. Current laws and regulations (max. flight height etc.)

g. Side and forward overlap percentages

Flight plans in this project have been prepared taking into consideration the above criteria's.

\subsubsection{Flight}

Between 20 and 25 February 2016, a flight of route of 270 $\mathrm{km}$ was performed. A total of $860 \mathrm{~km}$ was flown and 28.875 pictures were taken.

\subsubsection{UAV Platform Used}

The fixed-wing UAV platform used for the image data acquisition in our tests is shown in Figure 4, Technical Specifications in Table 3.

Fixed-wing is a term mainly used in the aviation industry to define aircraft that use fixed, static wings in combination with forward airspeed to generate lift. [5].

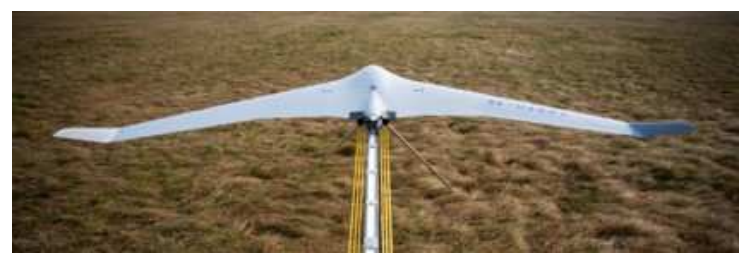

Figure 4. $U A V$.

Table 3. UAV Technical Specifications.

\begin{tabular}{ll}
\hline Parameter & Value \\
\hline Duration of the Flight & 160 minutes \\
Camera / Sensor & Sony A6000 \\
Data Link Distance & $40 \mathrm{~km}$ \\
Launch & Catapult \\
Landing & Parachute / Belly (skid) landing \\
Body frame material & Carbon/Kevlar \\
Wind Durability & 33 knots \\
Operating Temperature & $-25 \mathrm{C}$ between $+45 \mathrm{C}$ \\
\hline
\end{tabular}

\subsection{Photogrammetric Data Process Activities}

After passing through the following stages beloved, results data were obtained from the photographs taken by the UAV.

a. Taking of aerial photographs by using UAV (RAW, JPEG format)

b. Processing RTK data of captured photos. (Postprocessing)

c. Detection of faulty and unnecessary photos and radiometric corrections

d. Aerial Triangulation and adjustment by using Pix4D software

e. Quality Control of Aerial Triangulation

f. Point Cloud Generation

g. Digital Surface Model (DSM) and Colored True Orthophoto Production

h. Dense Cloud Classification and DTM generation

i. Volume Calculations

\subsubsection{Image Radiometry}

The radiometric quality of the images is critical in order to 
enable the application of quantitative remote sensing methodologies for a successful estimation of biophysical parameters from remote sensing imagery [6].

Photographs obtained using UAV (Figure 4). were recorded in RAW data format. Thus, it is possible to improve the obtained photographs with radiometric correction processes.
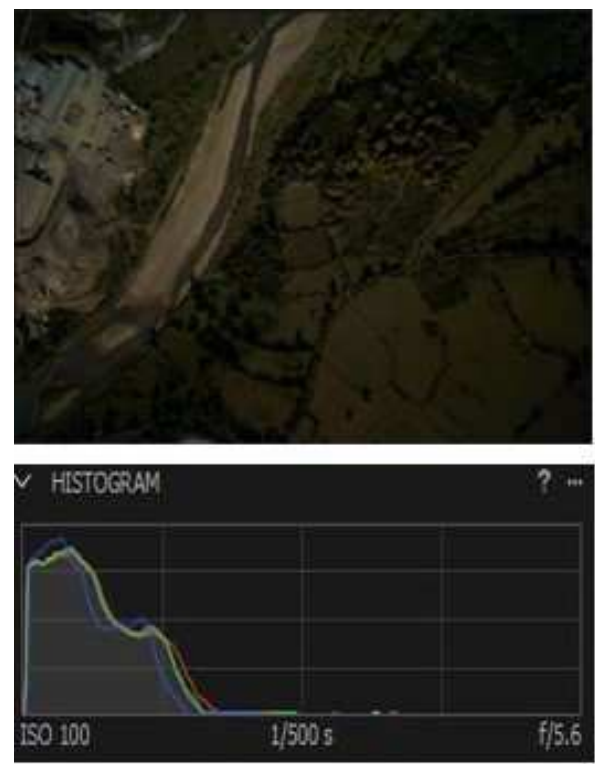

Figure 5. Before Correction.

Radiometric correction was performed by Capture One software and photographs shown in Figure 5 and Figure 6 were obtained.
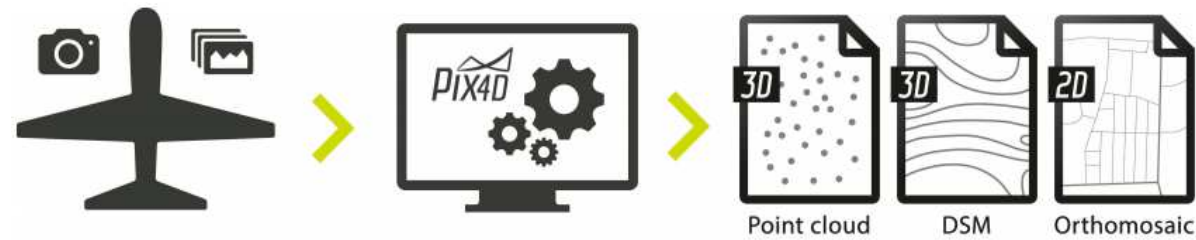

Figure 7. Steps in Data Process.

In this stage called "Initial Processing"( Figure 8), the algorithms and operations applied to the background can be listed as follows.

\section{Step 1: initial processing}

Images $=>$ calibrate cameras

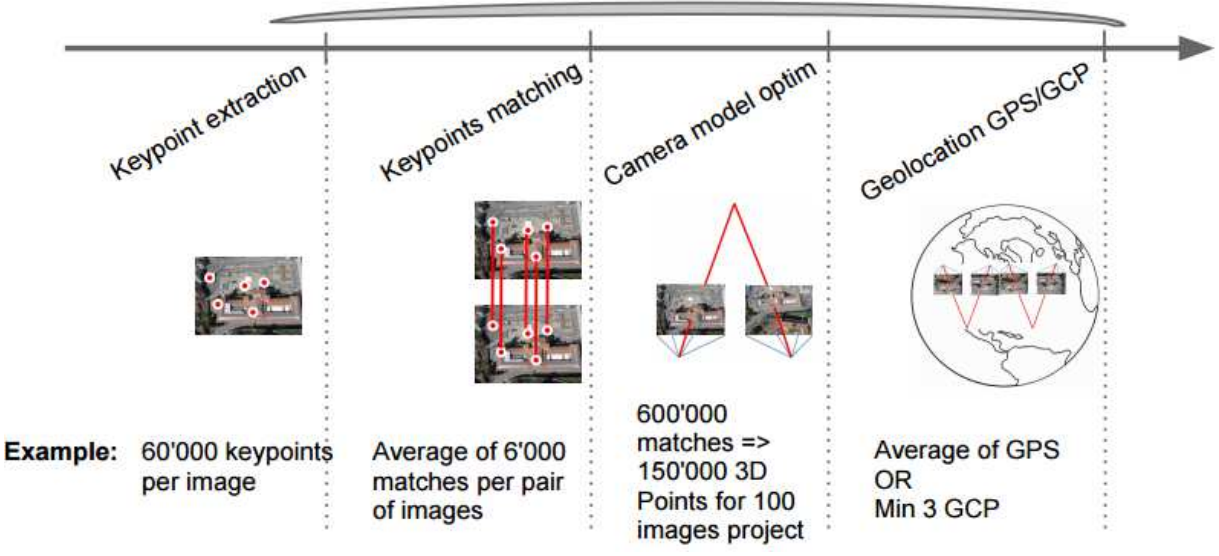

Figure 8. Initial Processing 
a. Keypoint Extraction: Finding similar points between pairs of images

b. Keypoint Matching: Matching up this keypoints with images

c. Camera Model Optimization: Calculation of camera internal and external parameters

d. Geolocation GPS/GCP: Geolocation of photographs using GPS and ground control points

The adjustment results (Figure 9) for a sample block of approximately $15 \mathrm{~km}$ long are realized as follows.

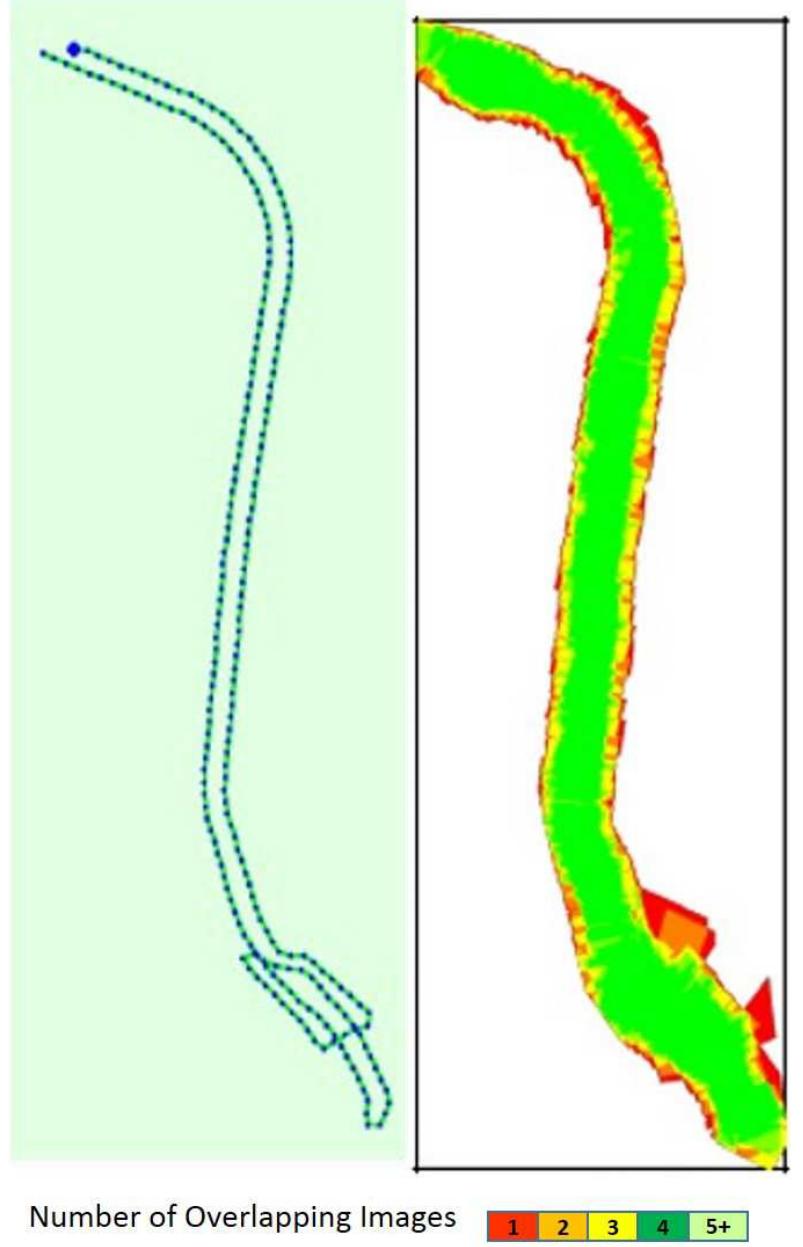

Figure 9. Adjustment Results.

Table 4. Root Mean Square Errors of Ground Control Points.

\begin{tabular}{|c|c|c|c|c|c|}
\hline GCP Name & Accuracy XY/Z (m) & Error X (m) & Error Y(m) & Erro Z (m) & Projection Error (pixel) \\
\hline 254690 (3D) & $0.020 / 0.020$ & 0.010 & 0.022 & 0.011 & 0.716 \\
\hline 254668 (3D) & $0.020 / 0.020$ & 0.036 & 0.035 & -0.035 & 0.117 \\
\hline 254650 (3D) & $0.020 / 0.020$ & 0.035 & 0.001 & -0.072 & 0.903 \\
\hline 254290 (3D) & $0.020 / 0.020$ & 0.026 & -0.038 & -0.032 & 0.274 \\
\hline 251900 (3D) & $0.020 / 0.020$ & -0.008 & 0.040 & -0.013 & 0.184 \\
\hline 251690 (3D) & $0.020 / 0.020$ & 0.060 & -0.040 & -0.053 & 0.377 \\
\hline 249890 (3D) & $0.020 / 0.020$ & -0.053 & -0.021 & 0.061 & 0.733 \\
\hline 29 (3D) & $0.020 / 0.020$ & -0.017 & 0.018 & -0.023 & 0.544 \\
\hline 31 (3D) & $0.020 / 0.020$ & -0.017 & -0.006 & -0.001 & 0.633 \\
\hline 253025 & $0.020 / 0.020$ & -0.020 & -0.003 & 0.005 & 1.348 \\
\hline $36(3 \mathrm{D})$ & $0.020 / 0.020$ & -0.008 & 0.008 & 0.008 & 0.893 \\
\hline 255050 (3D) & $0.020 / 0.020$ & 0.021 & 0.004 & -0.129 & 0.826 \\
\hline 254693 (3D) & $0.020 / 0.020$ & -0.050 & -0.027 & 0.013 & 1.436 \\
\hline 254557 (3D) & $0.020 / 0.020$ & -0.009 & -0.014 & 0.004 & 0.869 \\
\hline 254358 (3D) & $0.020 / 0.020$ & 0.027 & -0.002 & 0.050 & 1.329 \\
\hline 254259 (3D) & $0.020 / 0.020$ & -0.052 & 0.055 & -0.020 & 1.085 \\
\hline 253955 (3D) & $0.020 / 0.020$ & -0.004 & 0.006 & 0.009 & 0.465 \\
\hline 253770 (3D) & $0.020 / 0.020$ & 0.012 & 0.005 & -0.002 & 0.151 \\
\hline 253399 (3D) & $0.020 / 0.020$ & 0.010 & -0.003 & -0.010 & 0.453 \\
\hline
\end{tabular}




\begin{tabular}{llllll}
\hline GCP Name & Accuracy XY/Z (m) & Error X (m) & Error Y(m) & Erro Z (m) & Projection Error (pixel) \\
\hline 253251 (3D) & $0.020 / 0.020$ & 0.004 & 0.014 & 0.015 & 0.360 \\
252910 (3D) & $0.020 / 0.020$ & 0.042 & -0.017 & -0.016 & 0.138 \\
252791 (3D) & $0.020 / 0.020$ & -0.033 & 0.008 & 0.029 & 0.977 \\
252655 (3D) & $0.020 / 0.020$ & 0.009 & 0.008 & -0.006 & 0.627 \\
252418 (3D) & $0.020 / 0.020$ & 0.008 & -0.017 & 0.017 & 0.731 \\
252170 (3D) & $0.020 / 0.020$ & 0.021 & -0.025 & 0.029 & 1.090 \\
252060 (3D) & $0.020 / 0.020$ & 0.018 & 0.011 & 0.042 & 0.693 \\
251932 (3D) & $0.020 / 0.020$ & 0.006 & -0.030 & -0.021 & 0.793 \\
249921 (3D) & $0.020 / 0.020$ & 0.073 & -0.005 & -0.097 & 0.704 \\
249798 (3D) & $0.020 / 0.020$ & 0.004 & 0.066 & 0.120 & 0.645 \\
Mean (m) & & 0.003619 & 0.001529 & -0.002490 & \\
Sigma (m) & & 0.029298 & 0.022756 & 0.042584 & \\
RMS Error (m) & & 0.029521 & 0.022808 & 0.042657 & \\
\hline
\end{tabular}

As can be understood from the table, the horizontal and vertical root mean square errors (RMSEs) of Ground Control Points were realized as $+/-3 \mathrm{~cm}$ and $+/-4 \mathrm{~cm}$. and the camera parameters are also calculated as follows.

Table 5. Camera Parameters.

\begin{tabular}{|c|c|c|c|c|c|c|c|c|}
\hline & Focal Length & Principal Point $x$ & Principal Point y & R1 & $\mathbf{R 2}$ & $\mathbf{R 3}$ & T1 & $\mathrm{T} 2$ \\
\hline Initial Values & $\begin{array}{l}3.752 .228(\text { pixel }) \\
16.000(\mathrm{~mm})\end{array}$ & $\begin{array}{l}2.736 .000 \text { (pixel) } \\
11.667(\mathrm{~mm})\end{array}$ & $\begin{array}{l}1.824 .000(\text { pixel }) \\
7.778(\mathrm{~mm})\end{array}$ & 0.000 & 0.000 & 0.000 & 0.000 & 0.000 \\
\hline Optimized Values & $\begin{array}{l}3.788 .726(\text { pixel }) \\
16.156(\mathrm{~mm})\end{array}$ & $\begin{array}{l}\text { 2.632.044pixel) } \\
11.223(\mathrm{~mm})\end{array}$ & $\begin{array}{l}1.769 .007 \text { (pixel) } \\
7.543(\mathrm{~mm})\end{array}$ & -0.019 & 0.030 & -0.016 & -0.001 & -0.002 \\
\hline
\end{tabular}

\subsubsection{Point Clouds and Digital Surface Model (DSM) Generation}

Digital surface models (DSM) and orthophotos are the two main mapping products of UAV photogrammetry and remote sensing. In principle, once images are oriented and, possibly, calibrated, deriving DSM and orthophotos are routine tasks that have already been automated in photogrammetry and remote sensing since more than 20 years ago [9]

Technically point cloud is a data base containing points in three-dimensional coordinate system. However from the typical workflow perspective the only important thing is, that point cloud is a very accurate digital record of an object or space. It is saved in form of a very large number of points that cover surfaces of a sensed object.

In aerial adjustment, Point cloud is generated from photographs of which geodetic coordinates (X, Y, Z) and orientation Yaw Pitch Roll angles (Omega, Phi, Kappa) are combined and precisely calculated.

The Pix4D software generates point cloud in the form of DSM after balancing, and is offered to the user with a Point Cloud frequency option (Figure 10).
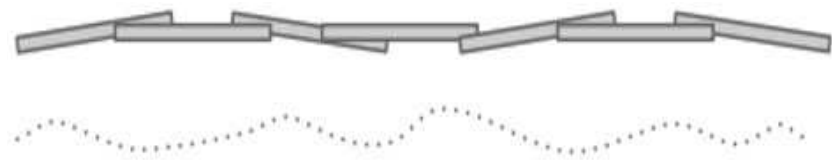

Figure 10. Photos-Point Cloud Schematic.

For this project, Point Cloud Generation has been referred as 2 pixel intervals.

\subsubsection{Point Cloud Classification and Digital Terrain Model (DTM) Generation}

The most critical and longest process in the project is point cloud classification. The raw point cloud generated in Pix4D is divided into Ground and Default classes by the operators.

The process steps in the Point Cloud classification (Figure 11) are as follows:

a. Application of the automatic classification macro to the Raw Point Cloud for batch processing in Terrasolid software

b. Rough Orthophoto creation

c. Cleaning and / or correction of defect points in the ground class that are automatically separated

d. Quality Control of Point Cloud Classification

e. Final Orthophoto creation

The obtained DTM cannot be used directly in CAD / GIS software because of it is composed of many points.

For this reason, sampling should be done without compromising on neither accuracy nor loss of data. This process is called "Model Key Point" creation

Creating "Model Keypoint" (Figure 12) to point of the sparse model without losing details of the terrain.

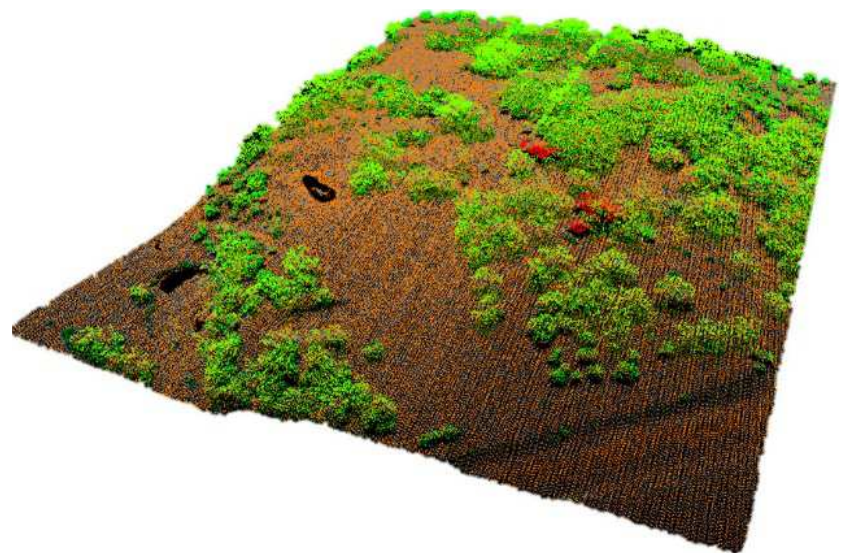

Figure 11. Point Cloud Classification. 

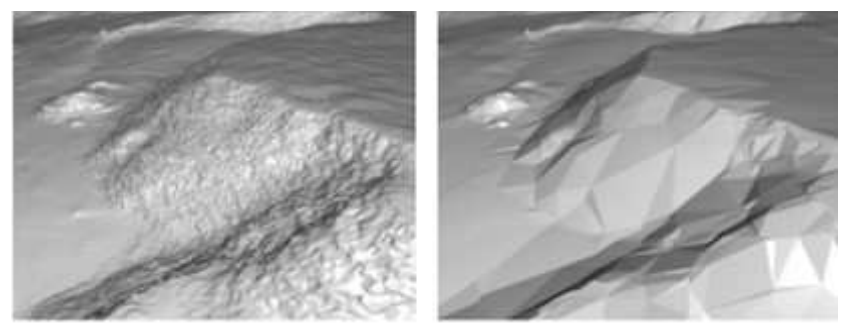

Figure 12. Model Keypoints.

\subsection{Orthophoto and Digital Surface Model (DSM) Production}

Following the production of Point Cloud, DSM has been developed. The DSM data consisting of all the details on the ground was created in Geotiff format.

Through the Pix4D software "Mosaic Editor" tool, the final orthophoto production has been completed by eliminating both color and geometric defects. In the Figure 14, the conceptual difference between DSM and DTM has been tried to be expressed.

Often they can be confusing and also misinterpreted to mean the same thing [10].

Digital Terrain Model (DTM)

A DTM is that represents the elevation of the bare earth without taking into account any over ground features (e.g. trees, buildings).

The DTM data of the Kombolcha/Ethiopia station area in the scope of the project is shown in Figure 13.

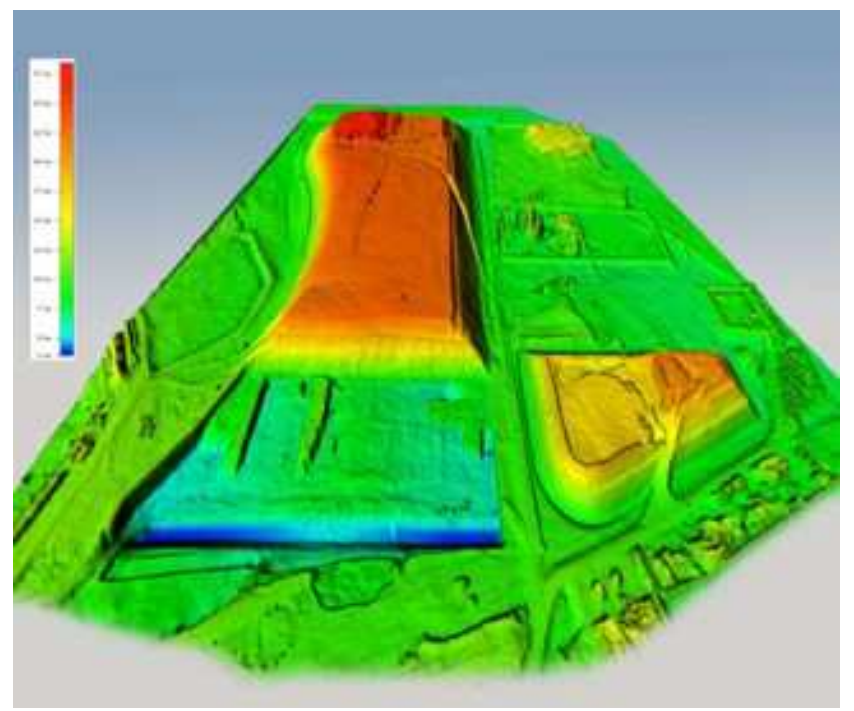

Figure 13. DTM (Digital Terrain Model).

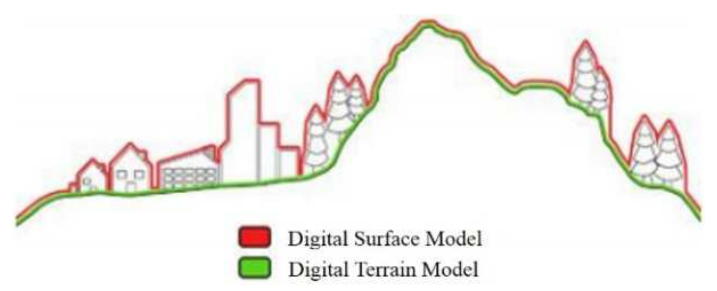

Figure 14. Conceptual Display of DTM \& DSM.

Digital Surface Model (DSM) is that represents the elevation of the surface a remote sensing system will first meet (i.e. when aerial photography is undertaken the top of a building, forest, etc.). Thus, the resulting DSM includes (Figure 14) the elevation of the bare earth terrain plus the natural (e.g. trees, shrubs) and man-made features (e.g. buildings).

Digital Terrain Models (DTMs) are getting more and more important in geographical data processing and analysis: they allow modelling, analysis and visualization of phenomena related to the territory morphology.

DTM accuracy should be consider to purpose of projects. The term precision is considered as a component of accuracy, related to the scale, resolution, and also to the generalization of datasets [11].

\subsection{Calculate the Volume of Cut/Fill and Analyzing \& Reporting}

Calculations the volume of cube were performed using Bentley In Roads software. By using excavation level (Figure 15), project level and raw terrain level (Figure 16) Obtained with flight data are used; amount of excavation and remaining excavation amounts as of the date of the flight are reported on each kilometer basis.

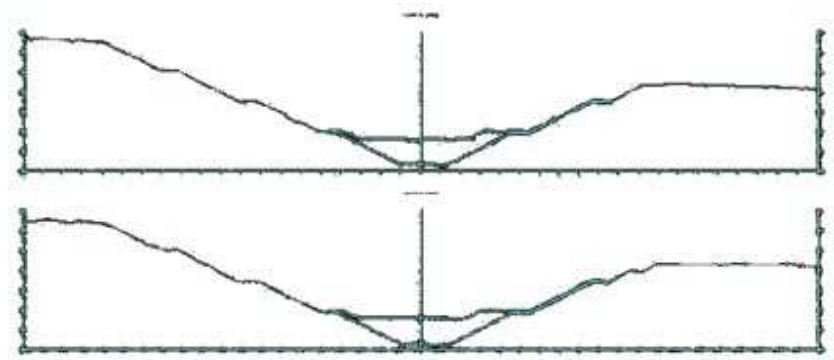

Figure 15. An Example of Cross Section.

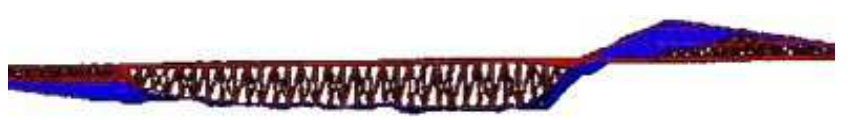

Figure 16. Example of Length Section.

DTM data and Orthophoto of the station area are shown in Figure 17 and Figure 18. Cube calculations in this area were made by taking the cross sections with $5 \mathrm{~m}$ intervals.

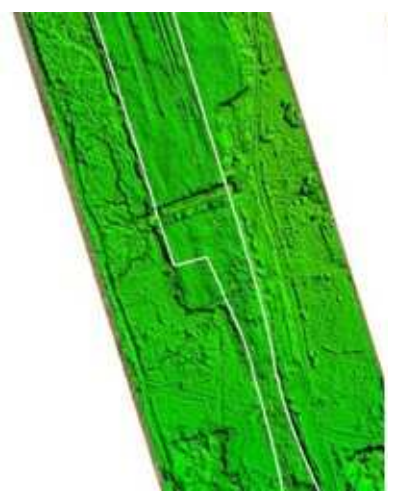

Figure 17. Station Region DTM. 


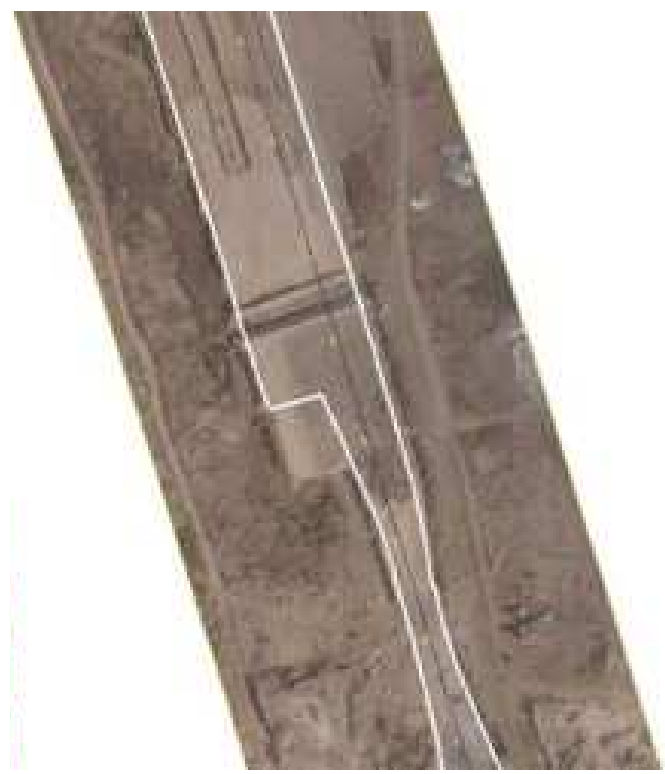

Figure 18. Station Region Orthophoto.

\section{Conclusions}

Owing to the final products obtained at the end of the project, project managers made better planning and made more accurate decisions.

At this point, the possible cost and time losses were prevented.

The duration of the project was 40 days including total flights considering the high accuracy of the obtained data, time and cost advantages, it is evaluated that the UAV-Based Photogrammetry can meet all kinds of mapping needs of such projects.

It is seen in this study, although UAV photogrammetry has many advantages relative to field surveying. Highly overlapped vertical aerial images of UAV photogrammetry are capable to make higher dense and more reliable spatial products [12].

UAV photogrammetry is a faster method for making higher quality, more reliable, and more diversity of products with legal validity, it costs several times less than field surveying due to its process automation without any huge field workings.

Major advantages of UAVs compared to manned aircraft systems are that UAVs can be used in high risk situations without endangering a human life and inaccessible areas, at low altitude and at flight profiles close to the objects where manned systems cannot be flown [13].

These advantages of UAV photogrammetry cause the fixed-wing UAV becomes a serious alternative for conventional field surveying in topographic map production

\section{References}

[1] Colomina, I and Molina, P, 2014. Unmanned aerial systems for photogrammetry and remote sensing: a review, ISPRS Journal of Photogrammetry and Remote Sensing, 92:82-95

[2] Przybilla, H.-J. and Wester-Ebbinghaus, W., 1979. Bildflug mit ferngelenktem Kleinflugzeug. Bildmessung und Luftbildwesen, Zeitschrift fuer Photogrammetrie und Fernerkundung, 47(5), pp. 135-140.

[3] Hongoh, D., Kajiwara, K. and Honda, Y., 2001. Developing ground truth measurement system using re helicopter and brdf model in forest area. In: 22nd Asian Conference on Remote Sensing, Vol. 5, Sigapore, p. 9.

[4] Demirel A. S., Akdeniz H., Aksu O., 2007, Two Functional Software for Internal use; Flight Planning and Presenting of Digital Orthophotos, a a Harita Genel Komutanlig1, 06100 Cebeci Ankara, Turkey - (sdemirel, hakdeniz, oaksu)@hgk.mil.tr Commission IV, WG IV/5.

[5] Vergouw B., Nagel H., Bondt G., and Custers B., 2006, Drone Technology: Types, Payloads, Applications, Frequency Spectrum Issues and Future Developments www.springer.com/cda/.../9789462651319-c2.pdf.

[6] Berni J. A., Suárez L, Dugo G., Fereres E.,, Remote Sensing of Vegetation From UAV Platforms Using Lightweight Multispectral and Thermal Imaging Sensors, InterCommission WG I/V.

[7] Qin, R., Grün, A., Huang, X., 2013. UAV Project - Building a Reality-Based 3D Model. Coordinates 9, 19-25.

[8] Tang, L., Braun, J., Debitsch, R. 1997,. Automatic Aerotriangulation - Concept, Realization and Results. ISPRS Journal of Photogrammetry \& Remote Sensing 52, 120- 130.

[9] Krzystek, P., 1991. Fully Automatic Measurement of Digital Elevation Models with MATCH-T. In: 43rd Photogrammetric Week. Institut für Photogrammetrie, Universität Stuttgart, Stuttgart, Germany, pp. 205-211.

[10] "Digital Elevation Models (DEM): Terrain (DTM) or Surface (DSM) Data?", https://www.pagerpower.com/news/differences-digitalelevation-model-dtm-dsm/

[11] Podobnikar T. 2005, Production of Integrated Digital Terrain Model From Multiple Datasets of Different Quality, IJGIS, 19/1, 71-86.

[12] Saadatseresht, M., A. H. Hashempourb, M. Hasanloua, 2015, UAV Photogrammetry: A Practical Solution For Mapping Projects, The International Archives of the Photogrammetry, Remote Sensing and Spatial Information Sciences, Volume XL-1/W5, 2015 International Conference on Sensors \& Models in Remote Sensing \& Photogrammetry, 23-25 Nov 2015, Kish Island, Iran.

[13] Eisenbeiss, H., 2009, Doctoral Thesis "UAV photogrammetry" Permanent Link: https://doi.org/10.3929/ethz-a-005939264. 